\title{
DIAGNOSIS OF DEVELOPMENT OPPORTUNITIES FOR REFRIGERATION SOCIO-TECHNICAL SYSTEM USING THE RADICAL INNOVATION DESIGN METHODOLOGY
}

\author{
Salehy, Yasmine (1,2); \\ Yannou, Bernard (1); \\ Leroy, Yann (1); \\ Cluzel, François (1); \\ Fournaison, Laurence (2); \\ Hoang, Hong-Minh (2); \\ Lecomte, Robin (1); \\ Delahaye, Anthony (2) \\ 1: Université Paris-Saclay, CentraleSupélec, Laboratoire Genie Industriel, Gif-sur-Yvette, France; \\ 2: Université Paris-Saclay, INRAE, FRISE, 92761, Antony, France
}

\begin{abstract}
A refrigerant system (like that of a supermarket) is a complex system if we consider all the stakeholders throughout its lifecycle phases (use, maintenance, technological update, end of life). The lack of stakeholders' interaction during the design and other lifecycle stages of such a system generates issues and leads to sub-optimal system performances. We used the RID methodology to identify the main areas for improvement for these activities related to the refrigerant system. It is precisely designed to analyze, within the scope of activity, the major stakeholders' problems (user profiles) during lifecycle phases (use situations) to deduce areas for improvement (value buckets). Therefore, we built a process of interviews and data collection on existing practices to feed into a RID model. The first results are an archetypal description of the actors and problems encountered according to the lifecycle phases. The second part is a prioritized mapping of the areas to improve despite a certain number of known available solutions but proven insufficient.
\end{abstract}

Keywords: Sociotechnical system, Innovation, Refrigeration, User centred design, Evaluation

\section{Contact:}

Salehy, Yasmine

Université Paris Saclay

Design Engineering

France

yasmine.salehy@centralesupelec.fr

Cite this article: Salehy, Y., Yannou, B., Leroy, Y., Cluzel, F., Fournaison, L., Hoang, H.-M., Lecomte, R., Delahaye, A. (2021) 'Diagnosis of Development Opportunities for Refrigeration Socio-Technical System Using the Radical Innovation Design Methodology', in Proceedings of the International Conference on Engineering Design (ICED21), Gothenburg, Sweden, 16-20 August 2021. DOI:10.1017/pds.2021.126 


\section{EXPLORING THE SOCIO-TECHNICAL SYSTEM OF REFRIGERATION SYSTEMS}

The impact of climate change on the refrigeration sector has resulted in drastically increasing demand for cold in the areas of food cooling, pharmaceuticals, buildings, supermarkets, transport (Schaeffer et al., 2012). Nearly $20 \%$ of the global electricity consumption is used for cold production, and it is expected to rise as the demand grows to reach $37 \%$ by 2050 (IEA, 2018). A refrigeration system (RS) works as a heat remover from the place to be chilled. It comprises five main elements: a compressor, a condenser, an evaporator, an expansion valve, and a refrigerant (flowing in the four previous elements). Different types of RSs exist depending on their use - domestic, commercial, transport, air conditioning -, regulation and technology. In the present study, we consider the retail refrigeration sector as the one of a supermarket for food preservation.

Refrigeration systems are subject to numerous regulations and laws to limit their high environmental impact. Indeed, they are energy-intensive systems that have been using refrigerants for decades, causing harmful impacts on the environment (Aprea et al., 2012; Islam et al., 2017). Managing a refrigeration system from its design to its end-of-life is tricky because of the number of disciplines, stakeholders and roles, and skills needed. Studies of refrigeration system solutions in retail have mainly focused on developing tools and technologies (Ben-Abdallah et al., 2019), optimizing one or multiple technical performances especially in the design stage under simplified conditions (Ge and Tassou, 2011; Kolokotroni et al., 2019), and understanding how an RS operates in a supermarket (Bahman et al., 2012). However, the lack of stakeholders interaction during the design and other lifecycle stages of such a system generates a range of problems and leads to sub-optimal system performances. To our knowledge, an adequate description and analysis of the socio-technical aspects of a RS have yet to be investigated. It implies the understanding of the infrastructure, the stakeholders, their role, the technology, the regulation, and the performances of RS. Our research objective was to identify the main areas for improvement for the activities related to the refrigerant system and the stakeholders' role. From this analysis, we wanted to deduce a prioritized list of improvement paths in order to innovate on a more integrated design strategy and platform that takes these improvement paths into account. The Radical Innovation Design RID methodology (Yannou, 2015; Yannou et al., 2016) is precisely designed to identify a system of activities, determine its improvement paths (called value buckets), and use them to increase the performance of the activity. With the aim of analyzing the often low environmental performances of a building, Lamé et al. (2017) used RID methodology to identify the imperfections of the socio-technical system of specification-design-implementation-usemaintenance of a building, the fragmentation in the activities of the actors, which explain why this environmental performance is not there. They were able to show the influence, or the lack thereof, or difficulties in implementing Life Cycle Assessment (LCA), eco-design approaches, and environmental standards, as well as the influence of the lack of consultation among the players in this value chain. In (Lamé et al., 2018), the authors analysed the activity system of a dental radiologist to derive value buckets from which they ideate for further defining innovative socio-technical layout solutions. In (Bekhradi et al., 2017), do-it-yourself activities are investigated to innovate on a universal accent light innovative solution. The interest of following a RID process is discussed in (Yannou et al., 2013).

We used the RID methodology to identify the main areas for improvement of the activities related to the refrigerant system (RS) and for analyzing the socio-technical system of an RS. The RID process first requires a careful investigation of an RS's socio-technical system which results in a first contribution: knowledge gathering on RS's socio-technical system in France. Then, the RID process demands to segmenting this knowledge into four dimensions to result in categories of stakeholders (called user profiles) who experience issues (called problems) during their activities, which are themselves segmented into lifecycle phases (called usage situations). The fourth dimension is the existing solutions that stakeholders may apply to diminish or remove an issue in a given activity. In an innovation approach, one must concentrate on value buckets (VB), for which existing solutions are of poor or no aid. These VB are defined as the major problems occurring for major stakeholders in frequent usage situations. Value buckets clearly indicate areas to innovate on where there is value to be created and few competitors; Blue Ocean Strategy (Kim and Mauborgne, 2005) calls them blue oceans. The second contribution of this paper is to identify and prioritize improvement areas in an RS's socio-technical system using RID methodology. These improvement areas are uncovered and commented on; they will serve us as justification in the development of a platform for the model-based design of a RS. 


\section{RID PROCESS AND PROCESS OF THIS STUDY}

\subsection{More on the RID methodology and process}

Radical Innovation Design is seen as a production process controlled and optimized thanks to a monitoring tower (the digital cockpit). Its objective is to innovate on a complex system while making a trade-off between the utility created for users to "augment" an activity's practice and the profit for a company in charge of this innovation in a competitive market. Figure 1 illustrates the RID production process of radical innovations. The production line (problem-setting followed by problem-solving) is run through once in its entirety. The run results in an ambition perimeter (the problem chosen to solve) and a new Product-Service-Organization (PSO) concept and Business Model (BM) which constitutes the new solution.

Decision making, under this new solution require two types of data visualization. The first answers the question "Where should we innovate? (For the benefit of users)" and is constituted by the matrix of Value Buckets. It is a kind of compass of innovation indicating important areas of problem-situationuser neglected by existing solutions. It truly orients towards blue oceans as described in Blue Ocean Strategy. The second type answers the question "What is the value of a solution (an existing one or a new one) regarding the potential to improve the activity, i.e. eradicate all value buckets?" Several types of "ratios of efficiency" indicators can be computed to compare efficiencies: globally, according to usage solutions, and according to problems.

Both types of data visualization facilities can be activated for a given user or all the users concerned by the activity, denoted "all the market" for simplicity. This second mode is activated by default, but the designers/marketers may choose, after an in-depth analysis, to address only a subset of user profiles.

Once the production line (see Figure 1) is run through a first time in its entirety, the profit of the company may be estimated for the resulting couple (ambition perimeter, new PSO concept + BM solution) from a market share estimation and a margin estimation. If this profit is not satisfactory, the designer/marketer may either revise his PSO concept and BM solution or revise first his ambition perimeter leading, in turn, to a new corresponding best PSO concept and BM solution. The innovation cockpit monitors this complex decision making and convergences process toward a preferred association (problem, solution).

For the present study, our audit of the socio-technical system of an RS corresponds to the grey dashes boundary in Figure 1; it only concerns most of the problem setting stage and the digital cockpit part.



Figure 1. The Radical Innovation Design is seen as a production process controlled and optimized thanks to a digital cockpit 


\subsection{Research process of this study}

Figure 2 displays the research process of our study in three stages.

The first stage consisted of an in-depth investigation of the socio-technical system of an RS in France. This stage corresponds to the Knowledge Design stage of a RID process (Yannou et al., 2016). We achieved (a) a literature review, (b) a ground analysis made of observations, expert interviews and reading of technical documentation. If no publications were found on commercial RS socio-technical analysis, the study's perimeter was extended to similar systems such as household refrigeration, buildings and energy systems (Cagno et al., 2019; Hesloin et al., 2017; Lamé et al., 2017; Mignon and Bergek, 2016). Ten stakeholders interviews in different companies and disciplines were conducted for context. The interviewees were at different levels of hierarchy, chosen according to their jobs and their availability. Each interview lasted around one hour and were semi-guided. The interviewees are questioned on six topics : identity (role, background, position along the value chain); current regulation and the anticipation; technology of the systems (limits, skills, development); design process; maintenance; sustainability positioning (also social and economic concerns). The technical documentations are related to standards, European legislation, maintenance procedures, instructions and product portfolio of refrigeration equipment manufacturers, documentation on software.

The second stage (see Section 3 for details) is an excerpt of the whole RID process of Figure 1 corresponding to the grey dashes boundary -, and is displayed more precisely to illustrate the data streaming. Seven matrices (represented in light grey) are built using the 4-dimension categories of user profiles, usage situations, problems and existing solutions. Then, these matrices are computed (see (Yannou et al., 2016)) to calculate where a company should innovate to respond simultaneously to create the expected values for the involved stakeholders and to address orphan value buckets, which are not directly addressed by existing solutions on the market. Several indicators are then computed allowing an in-depth analysis in Section 3: first, the MarketVB and DesignVB matrices of Value Buckets, and second a series of efficiency indicators for assessing the individual ability of each solution (existing or one) to eradicate, partially or totally, the identified issues (matrix WW).

In the third part (see Section 4 for details), we derive the two contributions to this study: a knowledge gathering on RS socio-technical system in France, and the identification and prioritization of opportunities of development in the socio-technical system of an RS.



Figure 2. Our study process and methodological framework

\section{KNOWLEDGE GATHERING ON RS SOCIO-TECHNICAL SYSTEM}

\subsection{Refrigeration systems lifecycle process}

Based on the data collected during the first phase of interviews and the literature review on the product lifecycle, we identify the main stages of a refrigeration system life-cycle (LC) as typical phases of a product lifecycle (Saaksvuori and Immonen, 2008; Stark, 2016): design, manufacture, installation, exploitation, and end-of-life (EOL) treatment as depicted in Figure 3.

In our study, we consider three main phases for the usage situations:

Design, manufacture and installation: it includes the stages of Engineering Design process (Pahl and Beitz, 2013), fabrication of the system, transport to the use space, and installation. We aggregated 
this first usage situation because of the difficulty in clearly distinguishing the boundaries of each of the stakeholders' activities in the initial stages.

Exploitation: it is the most extended phase. It includes the regular use of the system and the maintenance or repair occurring in this phase.

End-of-life (EOL): it is the shortest phase of the process. It consists of the dismantling, transportation, and EOL management for recycling, reuse, or incineration of the refrigeration system.

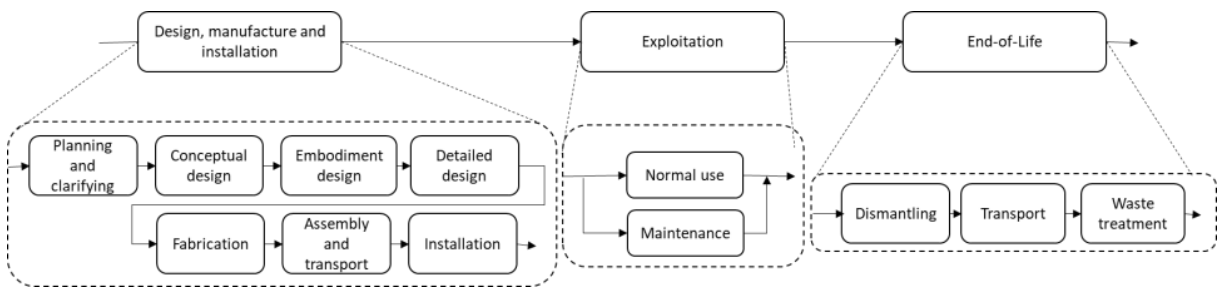

Figure 3. Commercial refrigeration system lifecycle process

\subsection{Users involved in the RS organizational process}

Since the beginning of a strict regulation with the 1987 Montreal Protocol, changing existing installations has proven difficult. Since 2015, the F-gas law regulates refrigerant use to reach the exclusive use of natural gases in industrial machines by 2030. Centuries' worth of experience, knowledge and know-how had to be rebuilt in a matter of decades. This evolution tests the flexibility of companies to respond to regulation. This section provides knowledge of the current stakeholders' organizational process. The semi-guided interviews provide answers from the field concerning the stakeholders' interaction with each other, when in the process, what their activities were, and the problems they encountered to complete their tasks. The interviews highlight the fragmented process of managing a refrigeration system. The interviewees had different images of the global socio-technical system, especially the tasks and activities boundaries of each stakeholders. They nonetheless provided a unanimous answer on the key roles, the constraints of adapting to the actors they interact with (budget, deadlines, and company's mindset) and the evolution of the sector.

Most of the users are involved in the first stage described previously. During this stage, the final user of the RS (for example a supermarket) interacts only with one actor: a supplier. The supplier is the most important stakeholder, whose role is to link manufacturing to final use. The supplier also has the specific characteristic of being involved at every LC stage. Once the machine is installed and running, the only stakeholders concerned by the exploitation phase are the final user (as the machine's daily user) and the refrigeration engineers through the intermediary of the supplier for maintenance tasks. In the final stage of the system LC, the activities of EOL treatment parties are limited to the transport and treatment of the machine. The refrigeration technicians from the supply company oversee emptying the refrigerant in the machine. The system's final user is involved from time to time in the EOL of the system, but it is mostly the supplier company's responsibility. The described interactions are show in Figure 4.

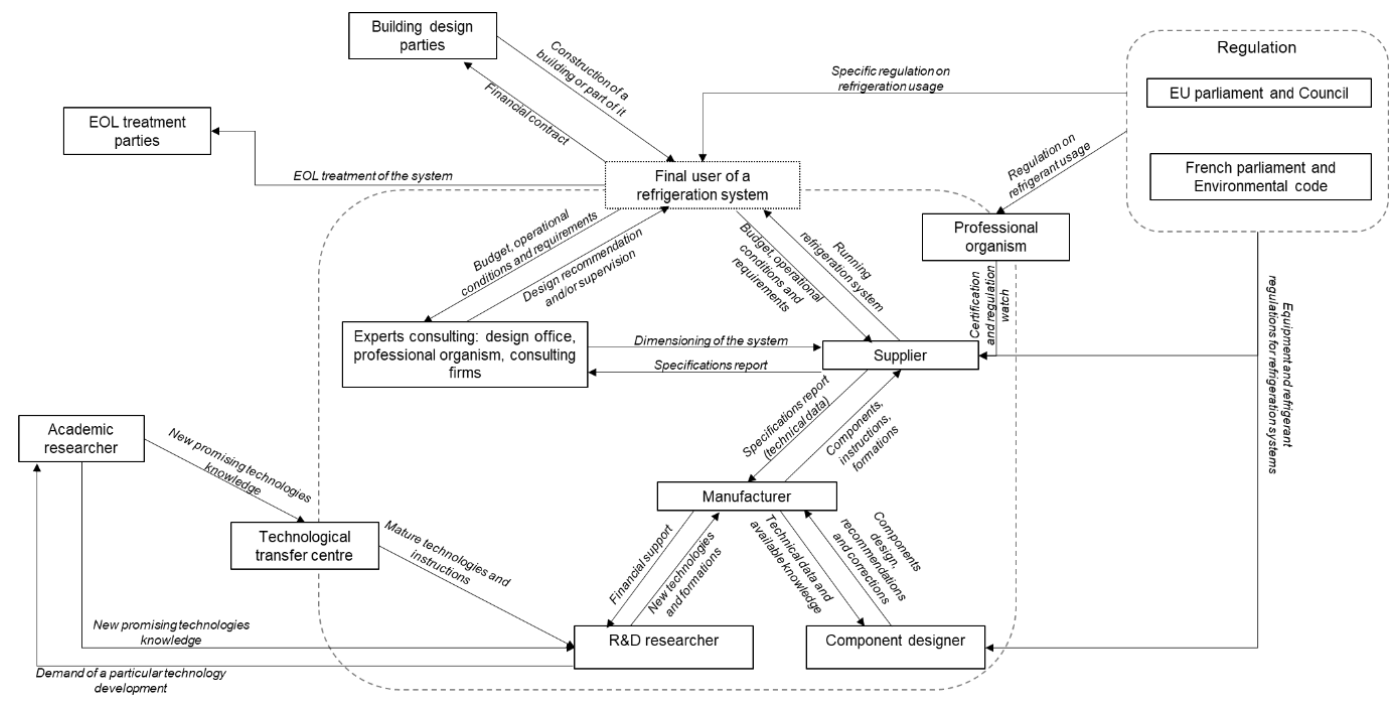

Figure 4. Definition of the 12 categories of user profiles and interaction diagram between them 


\subsection{Issues in the current process}

The issues presented are the results of the interviews and the literature review. They are either specific to one or common to multiple usage situations. We collect the issues occurring in the design and the exploitation phases from the interviews. The EOL treatment phase gaps were documented by (Ardente et al., 2015) and updated with the experts' interviews. Then, we categorize them according to typology in four main categories, i.e., costs, knowledge management, and interaction between stakeholders, and tools, adapted from (Pärttö and Saariluoma, 2012) and summarized in Table 1.

Table 1. List of main problems identified in all the phases and classified in four categories.

\begin{tabular}{l|l} 
Problem category & Problem identified \\
\hline \multirow{5}{*}{ Cost } & Risk of early obsolescence \\
\cline { 2 - 2 } & Risk of unexpected investment costs \\
\cline { 2 - 2 } & Risk of break down \\
\cline { 2 - 2 } Knowledge management & Risk of high operational costs (OPEX) \\
\hline \multirow{5}{*}{ Interactions between stakeholders } & Decrease of the recruitment quality \\
\cline { 2 - 2 } & Lack of refrigeration technicians and engineers \\
\cline { 2 - 2 } & Lack of understanding of new technological clusters \\
\hline & Disturbed process of advice to the final usage of the system \\
\cline { 2 - 2 } & Lack of flexibility for the installers \\
\cline { 2 - 2 } & Risk of discomfort for the final user's customers \\
\cline { 2 - 2 } & Risk of high danger for human health \\
\hline \multirow{5}{*}{ Tool } & Poor exploration of the design space \\
\cline { 2 - 2 } & Lack of common efficient tools \\
\cline { 2 - 2 } & Risk of high environmental impacts \\
\cline { 2 - 2 } & Poor recycling rate
\end{tabular}

\subsubsection{Costs}

There is a need for a quick change in the systems to respond to the evolution of regulation. The lack of companies' structural adaptability makes the risk of high costs inevitable. In the exploitation phase, the risk increases with the possibility of a component's obsolescence, human error, and refrigerant leakage. The impact is an increase in costs for the final user mostly. Moreover, the lack of knowledge on the possibility of EOL parties to treat their waste sometimes leads to waste left on-site and thus causing poor recycling rate. During the exploitation, breakdowns are frequent but not fatal as the system functions remain robust. They can be mechanical, electric, or design-related breakdowns and can lead to high repair costs or loss of frozen food. The electric consumption of the system is the most critical operational cost. The most frequent reasons are maintaining systems and energy loss (Evans et al., 2014).

\subsubsection{Knowledge management}

As the sector is changing, the training of new technicians or engineers decreases. As industrial demand increases, the refrigeration sector lacks refrigeration technicians or engineers. SNEFFCA, a professional union, reports recruitment rate in the sector as more than 4000 recruitments per year for 2000 small or medium companies, with a reducing number of applications. In all the usage situations, new technological clusters are often not fully understood as there is no time to keep up with the changes.

\subsubsection{Interaction between stakeholders}

A change in regulation results in a disturbance of the process of advice for the final user; the recommendations are thus not optimal. During the design phase, a frequent problem is that the final user specifications given to the supplier can constrain the design space. During the exploitation phase, either during regular use or maintenance, customers can hear an uncomfortable noise. This problem is not frequent and has no significant damage to the users but can harm the company's image. Moreover, the refrigerant's use can cause human health problems (toxic or flammable refrigerant) or highpressure equipment such as $\mathrm{CO}_{2}$-based systems. Accidents, while extremely rare, are fatal.

\subsubsection{Tool}

During the RS design phase, most design offices are subject to a strong time constraint that prevents an optimal design space exploration. More than a hundred types of tools exist to design a RS, but they are not considered entirely efficient. Most companies use Life Cycle Assessment (LCA) to calculate the environmental impacts of the systems. The exploitation and the EOL treatment phases carry a 
higher risk of higher negative impacts due to frequent refrigerant leakage and high electric consumption resulting in high indirect impacts (Salehy et al., 2019). However, it does not consider the EOL when large industrial systems components are sometimes left on-site mostly because of higher costs of dismantling components or lack of knowledge of the EOL treatment parties that can manage the EOL.

\subsection{Existing solutions}

For each of the usage situations defined previously, the users have different solutions that can help them accomplish their tasks and appease the problems they encounter. We identified 6 different solution categories (Table 2).

Table 2. The six categories of existing solutions identified.

\begin{tabular}{l|l} 
Identified solutions categories & Characterization \\
\hline Software-based solutions & $\begin{array}{l}\text { Programs and instructions to design and monitor refrigeration } \\
\text { systems during each usage situations. }\end{array}$ \\
\hline $\begin{array}{l}\text { Knowledge management (KM) } \\
\text { based solutions }\end{array}$ & $\begin{array}{l}\text { Documents, best practices guides, and technics to guide, } \\
\text { improve the activities, and make the users aware during each } \\
\text { usage situation }\end{array}$ \\
\hline \multirow{2}{*}{ Methodological solutions } & $\begin{array}{l}\text { Methods and approaches used in the design phase to palliate } \\
\text { potential problems occurring in the exploitation and EOL } \\
\text { phases }\end{array}$ \\
\hline Technological solutions & $\begin{array}{l}\text { Technological clusters (at all readiness levels) that can be used } \\
\text { in all the usage situations }\end{array}$ \\
\hline \multirow{2}{*}{ Tool solutions } & $\begin{array}{l}\text { All the tangible tools used for the RS's installation, } \\
\text { maintenance, dismantling, and EOL treatment }\end{array}$ \\
\hline \multirow{2}{*}{ EN 378(2017) } & $\begin{array}{l}\text { Norm guidelines. It is the only specific solution used in this } \\
\text { data treatment }\end{array}$ \\
\cline { 2 - 2 }
\end{tabular}

\section{RESULTS}

\subsection{Data treatment}

The whole RS lifecycle is investigated. In the RID analysis matrices, data are classified into four distinguished dimensions. First, the three macro LC phases are retained as usage situations given the challenge of distinguishing the stakeholder's activities for each sub-phases with the collected data. Second, there are fifteen current problems identified. We consider the users profiles as stakeholders directly concerned in the project. We identified twelve of them (cf. 3.2). The existing solutions are numerous, and we identified six categories of solutions to reduce the complexity of the analysis.

The matrices in light grey from Figure 2 are then filled with quantifying data on a scale from $0=$ never to $5=$ frequently based on the qualitative data collected. Table 3 provides an example of matrix filling. It quantifies the usefulness of the existing solution categories in each usage situation driven by the interviews and observations. Actors can use a single solution during their activities or a combination of different solutions from the same category or different categories. For example, during the design phase, most activities are made with software solutions such as AutoCAD for the system drawings and Excel sheets for the calculation of the frigorific power, compressor needed, and sometimes by the EN378 guidelines and/or methodological solutions. Technical solutions and tools are only used to manufacture components or put the system in place.

Table 3. UsEs matrix: At what extend does this existing solution facilitate the usage situation? (Scale from $0=$ never to $5=$ frequently)

\begin{tabular}{|c|c|c|c|c|c|c|}
\hline & $\begin{array}{l}\text { Software } \\
\text { solutions }\end{array}$ & $\begin{array}{l}\text { KM } \\
\text { solutions }\end{array}$ & $\begin{array}{l}\text { EN } 378 \\
\text { guidelines }\end{array}$ & $\begin{array}{l}\text { Methodological } \\
\text { solutions }\end{array}$ & $\begin{array}{l}\text { Technologic } \\
\text { al solutions }\end{array}$ & $\begin{array}{l}\text { Tool } \\
\text { solutions }\end{array}$ \\
\hline $\begin{array}{l}\text { Design, } \\
\text { manufacture } \\
\text { and } \\
\text { installation }\end{array}$ & (5) & (5) & 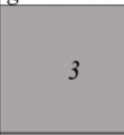 & - & we & 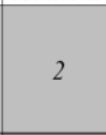 \\
\hline Exploitation & 4 & 5 & 4 & 4 & 4 & 5 \\
\hline End-of-life & 3 & 4 & 4 & 3 & 2 & 5 \\
\hline
\end{tabular}

The opportunities of development are highlighted with the calculation of the Value Buckets (see Figure 1). The three most important VBs occur during the first usage situation. It is the most complex stage because many stakeholders are involved, each with their own way of acting.

The three VBs identified by the Value Bucket algorithm (Table 4) are:

- $\quad$ VB1: lack of understanding, i.e., adaptation of the new technological clusters (\#7). 
- VB2: disturbed process of interaction between stakeholders, i.e., the organizational structure in the process $(\# 8,9)$.

- VB3: lack of common tool, i.e., the shared knowledge to all the users involved in the project (including EOL) with an involving technological cluster database (\#13).

Table 4. Results of the DSM value bucket tool with the three VB identified

\begin{tabular}{|c|c|c|c|c|c|c|c|c|c|c|c|c|c|c|c|}
\hline & \multicolumn{4}{|c|}{$\underline{\operatorname{Cos} t}$} & \multicolumn{3}{|c|}{$\begin{array}{l}\text { Knowledge } \\
\text { management }\end{array}$} & \multicolumn{4}{|c|}{$\begin{array}{l}\begin{array}{l}\text { Interactions between } \\
\text { stakeholders }\end{array} \\
\end{array}$} & \multicolumn{4}{|l|}{$\underline{\text { Tool }}$} \\
\hline & 1 & 2 & 3 & 4 & 5 & 6 & 7 & 8 & 9 & 10 & 11 & 12 & 13 & 14 & 15 \\
\hline $\begin{array}{l}\text { Design, } \\
\text { manufacture } \\
\text { and } \\
\text { installation }\end{array}$ & 0,06 & 0,05 & 0 & 0 & 0,14 & 0,2 & & 34 & 0,26 & 0 & 0 & 07 & 0,35 & 0 & 0 \\
\hline Exploitation & 0,01 & 0 & 0,08 & 0,02 & 0 & 0,09 & 0,07 & 0,00 & 0 & 0,05 & 0 & 0 & 0 & 0,06 & 0 \\
\hline End-of-life & 0 & 0 & 0 & 0 & 0 & 0 & 0,02 & 0,01 & 0 & 0 & 0 & 0 & 0 & 0,01 & 0 \\
\hline
\end{tabular}

Figure 5 shows one of the efficiency indicators: the relative efficiency of each group of solutions to respond to the problems in the process. It indicates the percentage of satisfaction of each solution for each problem. A value of 1 means that the solution answers perfectly to the problem whereas a value of 0 means no solution eradicates this problem. The only helpful solutions for knowledge management related problem is training. However, interviewees emphasize that the training courses arrive when a stakeholder find himself in a critical situation (such as working with a $\mathrm{CO}_{2}$-based system).



Figure 5. Ratios of efficiency of the existing solutions for the current problems (in terms of percentage of problems' possible eradication, whatever usage situations and user profiles)

\subsection{Analysis of the opportunities for development}

Even though the interviewees' most crucial category of issues is cost, it does not appear in the Value Buckets (VB). The systematic care of operational conditions, i.e., regular maintenance, backup mode to prevent a complete stop from the machine, change of non-optimal components, can explain it. Moreover, a national financial incentive such as "CEE" in France to change installation encourages companies to improve their system. The refrigeration sector was one of the industrial fields to be the first impacted and made aware of environmental consequences. Thus, reducing the system's environmental impacts is not rated important in the VB as the interviewees consider that there are solutions such as eco-design tools and technologies such as natural refrigerant to reduce the emissions. The EOL is the less rated usage situation. As a refrigeration system is considered a WEEE, the solutions to manage its EOL once the technicians empty the refrigerant are highly developed. The only important challenge for the EOL parties is the need to be informed of disruptive technological change. They need to be aware of the technologies' development in case of an EOL management's change.

During the exploitation phase, the system robustness influences the problems encountered. As refrigeration systems are robust due to extensive research on optimizing the system, interviewees do not currently indicate this stage as the most challenging one. However, as the summers are getting hotter, more and more system run as least once on the back up degraded mode. In the years to come, refrigeration technicians and project managers consider that they will have to face the problems of providing a system that can run during the most critical peak of cold need (typically the hottest day of the year).

More than a hundred tool solutions exist. However, the relative efficiency of the solutions presented in Figure 5 highlights that they do not meet the current industrial problems. Moreover, the problems of 
knowledge management and interaction between stakeholders do not have many possible solutions. It is one of the issues most difficult to manage for the user interviewed. We observed a confusion from the stakeholders about the whole socio-technical system mostly because of the high number of companies, regulation, solutions and possibilities.

The Value Bucket algorithm points out the importance of the design, manufacture, and installation phase. Indeed, this usage situation is considered for the interviewees to be the most challenging one: it is the stage during which multiple actors from different companies or teams collaborate, bringing their knowledge, preferences, tools, and experience.

Knowledge management and interaction between stakeholders are two important problem categories identified by (Pärttö and Saariluoma, 2012) that explain failures in design. In the last decades, research in refrigeration developed promising technologies. The stakeholders have difficulties investing in these new technologies because of the lack of visibility in the long term. Refrigeration systems are robust and expensive to develop. Technical change towards more sustainable systems should consider the users and the usage situation. Thus, the proposed solution to respond to the gaps identified in the value buckets is given in two distinct parts: developing an integrated approach and a new organizational process. It consists of modeling and simulating a refrigeration system in usage on a common platform. Technical performances and industrial performances such as maintenance, space used, ease of installation, investment, and operational costs will be calculated. From the simulation results, appropriate recommendations will be given to the user, such as the necessity of company development. A set of scenarios will validate the platform. A new organizational process proposition will be compared to the existing one by iteration with experts.

The same RID methodology will assess the solution's relevance to validate the approach and fill the current value buckets.

\section{CONCLUSION}

Our objective is to improve the global design of a refrigeration system (RS) for the food industry (typically the one in a supermarket). We analyze the areas of improvement of the socio-technical system lifecycle stages of the RS, by asking the question: Are the causes of poor system performance due to a lack of tools, a lack of design know-how, or a whole set of organizational problems due to a lack of consultation between the players in the value chain?

Radical Innovation Design proved to be efficient for analyzing complex socio-technical systems made of a set of activities, to result in prioritized value buckets and efficiency indicators, after a series of precise steps: an in-depth investigation, a segmentation of four objects, the evaluation of their relationships through the filling of seven matrices, and finally the computation of resulting value buckets and efficiency indicators (Figure 2).

A ground study provides the necessary data to fill the matrices. During the interviews, the issues revealed the importance of the first step in a refrigeration system's lifecycle. Different actors are involved in the process, and yet they lack interaction between them. The Value Bucket algorithm pushed forward three main stakeholders' problems during the first lifecycle stage. They concern the interaction between stakeholders, the comprehension of new technologies, and the lack of a common tool corresponding to all stakeholders' expectations.

This analysis allows us now to start from these identified value buckets to develop a twofold innovative solution. On the one hand, we are developing an integrated platform for modeling and simulating the refrigerant system under design and, on the other hand, a set of recommendations for a new multi-actor organization over an RS lifecycle. For the integrated platform, we will better integrate stakeholders' constraints (budget, mindset, company's image, deadline, operational and installation conditions) and simplified models of RS performances that were not considered by existing platforms to assess them earlier in the design process. Let us mention performances such as the maintenance costs and ease, the availability performance, the space used, the adaptation to the regulation's evolution. Lastly, the RID methodology will permit, once our innovation solution developed, to assess its global ability to eradicate the identified value buckets so as the complete the innovation cycle.

\section{REFERENCES}

Aprea, C., Greco, A., Maiorino, A., 2012. An experimental evaluation of the greenhouse effect in the substitution of R134a with CO2. Energy 45, 753-761. https://doi.org/10.1016/j.energy.2012.07.015 
Ardente, F., Calero Pastor, M., Mathieux, F., Talens Peiró, L., 2015. Analysis of end-of-life treatments of commercial refrigerating appliances: Bridging product and waste policies. Resources, Conservation and Recycling 101, 42-52. https://doi.org/10.1016/j.resconrec.2015.05.005

Bahman, A., Rosario, L., Rahman, M.M., 2012. Analysis of energy savings in a supermarket refrigeration/HVAC system. Applied Energy 98, 11-21. https://doi.org/10.1016/j.apenergy.2012.02.043

Bekhradi, A., Yannou, B., Cluzel, F., Vallette, T., 2017. Categorizing user pains, usage situations and existing solutions in front end of innovation: the case of smart lighting project, in: 21st International Conference on Engineering Design (ICED 17). Vancouver, Canada.

Ben-Abdallah, R., Leducq, D., Hoang, H.M., Fournaison, L., Pateau, O., Ballot-Miguet, B., Delahaye, A., 2019. Experimental investigation of the use of PCM in an open display cabinet for energy management purposes. Energy Conversion and Management 198, 111909. https://doi.org/10.1016/j.enconman.2019.111909

Cagno, E., Neri, A., Howard, M., Brenna, G., Trianni, A., 2019. Industrial sustainability performance measurement systems: A novel framework. Journal of Cleaner Production 230, 1354-1375. https://doi.org/10.1016/j.jclepro.2019.05.021

Evans, J.A., Hammond, E.C., Gigiel, A.J., Fostera, A.M., Reinholdt, L., Fikiin, K., Zilio, C., 2014. Assessment of methods to reduce the energy consumption of food cold stores. Applied Thermal Engineering 62, 697-705. https://doi.org/10.1016/j.applthermaleng.2013.10.023

Ge, Y.T., Tassou, S.A., 2011. Performance evaluation and optimal design of supermarket refrigeration systems with supermarket model "SuperSim", Part I: Model description and validation. International Journal of Refrigeration 34, 527-539. https://doi.org/10.1016/j.ijrefrig.2010.11.010

Hesloin, C., Perry, N., Perrot-Bernardet, V., 2017. Consideration of value chain actors in the analysis of environmental performance for eco-design and incentive for sustainable behavior : case study of energyusing products road transport refrigeration units. Ecole nationale supérieure d'arts et métiers - ENSAM.

IEA, 2018. The future of cooling. International Energy Agency, Paris.

Islam, Md. A., Srinivasan, K., Thu, K., Saha, B.B., 2017. Assessment of total equivalent warming impact (TEWI) of supermarket refrigeration systems. International Journal of Hydrogen Energy 42, 26973-26983. https://doi.org/10.1016/j.ijhydene.2017.07.035

Kim, W.C., Mauborgne, R., 2005. Value innovation: a leap into the blue ocean. Journal of business strategy.

Kolokotroni, M., Mylona, Z., Evans, J., Foster, A., Liddiard, R., 2019. Supermarket Energy Use in the UK. Energy Procedia 161, 325-332. https://doi.org/10.1016/j.egypro.2019.02.108

Lamé, G., Leroy, Y., Yannou, B., 2017. Ecodesign tools in the construction sector: Analyzing usage inadequacies with designers' needs. Journ. of Cleaner Prod. 148, 60-72, https://dx.doi.org/10.1016/j.jclepro.2017.01.173

Lamé, G., Yannou, B., Cluzel, F., 2018. Usage-driven problem design for radical innovation in healthcare. BMJ Innovations.

Mignon, I., Bergek, A., 2016. System- and actor-level challenges for diffusion of renewable electricity technologies: an international comparison. Journal of Cleaner Production 128, 105-115. https://doi.org/10.1016/j.jclepro.2015.09.048

NF EN 378 - Refrigerating systems and heat pumps - Safety and environmental requirements, 2017. European Committee for Standardisation.

Pahl, G., Beitz, W., 2013. Engineering design: a systematic approach. Springer Science \& Business Media.

Pärttö, M., Saariluoma, P., 2012. Explaining failures in innovative thought processes in engineering design. Procedia - Social and Behavioral Sciences 41, 442-449. https://doi.org/10.1016/j.sbspro.2012.04.053

Saaksvuori, A., Immonen, A., 2008. Product lifecycle management. Springer Science \& Business Media.

Salehy, Y., Leroy, Y., Cluzel, F., Hoang, H.-M., Fournaison, L., Delahaye, A., YANNOU, B., 2019. Life cycle assessment of hypermarket refrigeration system: effet of location and choice of architecture, in: AvniR Conference. Lille, France.

Schaeffer, R., Szklo, A.S., Pereira de Lucena, A.F., Moreira Cesar Borba, B.S., Pupo Nogueira, L.P., Fleming, F.P., Troccoli, A., Harrison, M., Boulahya, M.S., 2012. Energy sector vulnerability to climate change: A review. Energy 38, 1-12. https://doi.org/10.1016/j.energy.2011.11.056

Stark, J., 2016. Product lifecycle management, in: Product Lifecycle Management (Volume 2). Springer, 1-35.

Yannou, B., 2015. Supporting need seeker innovation: the Radical Innovation Design methodology, in: International Conference on Engineering Design (ICED). Milano, Italy.

Yannou, B., Cluzel, F., Farel, R., 2016. Capturing the relevant problems leading to pain- and usage-driven innovations: The Dependency Structure Modeling Value Bucket algorithm. Concurrent Engineering 26, 131-146. https://doi.org/10.1177/1063293X16666311

Yannou, B., Jankovic, M., Leroy, Y., Okudan Kremer, G.E., 2013. Observations From Radical Innovation Projects Considering the Company Context. Journal of Mechanical Design 135. https://doi.org/10.1115/1.4023150 